\title{
Synthesis of (-)-7-Deacetoxyalcyonin Acetate
}

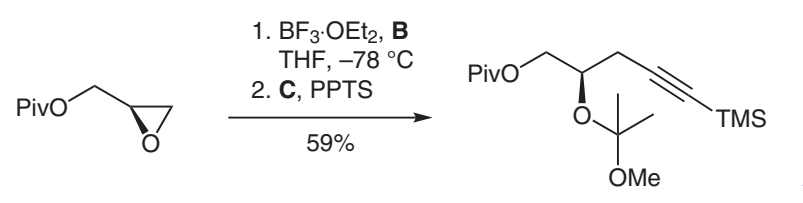

A

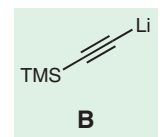

B

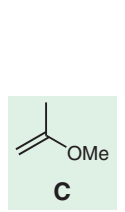

D<smiles>CC(C=O)=CCO[Sb]</smiles>
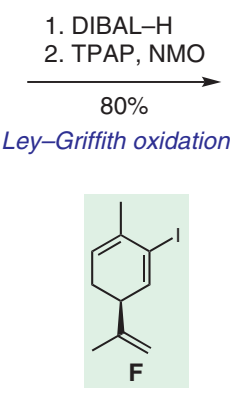

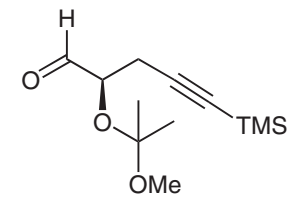

E

Synthesis of Natural

Products and

Potential Drugs

\section{Key words}

eunicellin diterpenes

Prins-pinacol rearrangement

photolytic

deformylation

Nozaki-HiyamaKishi reaction
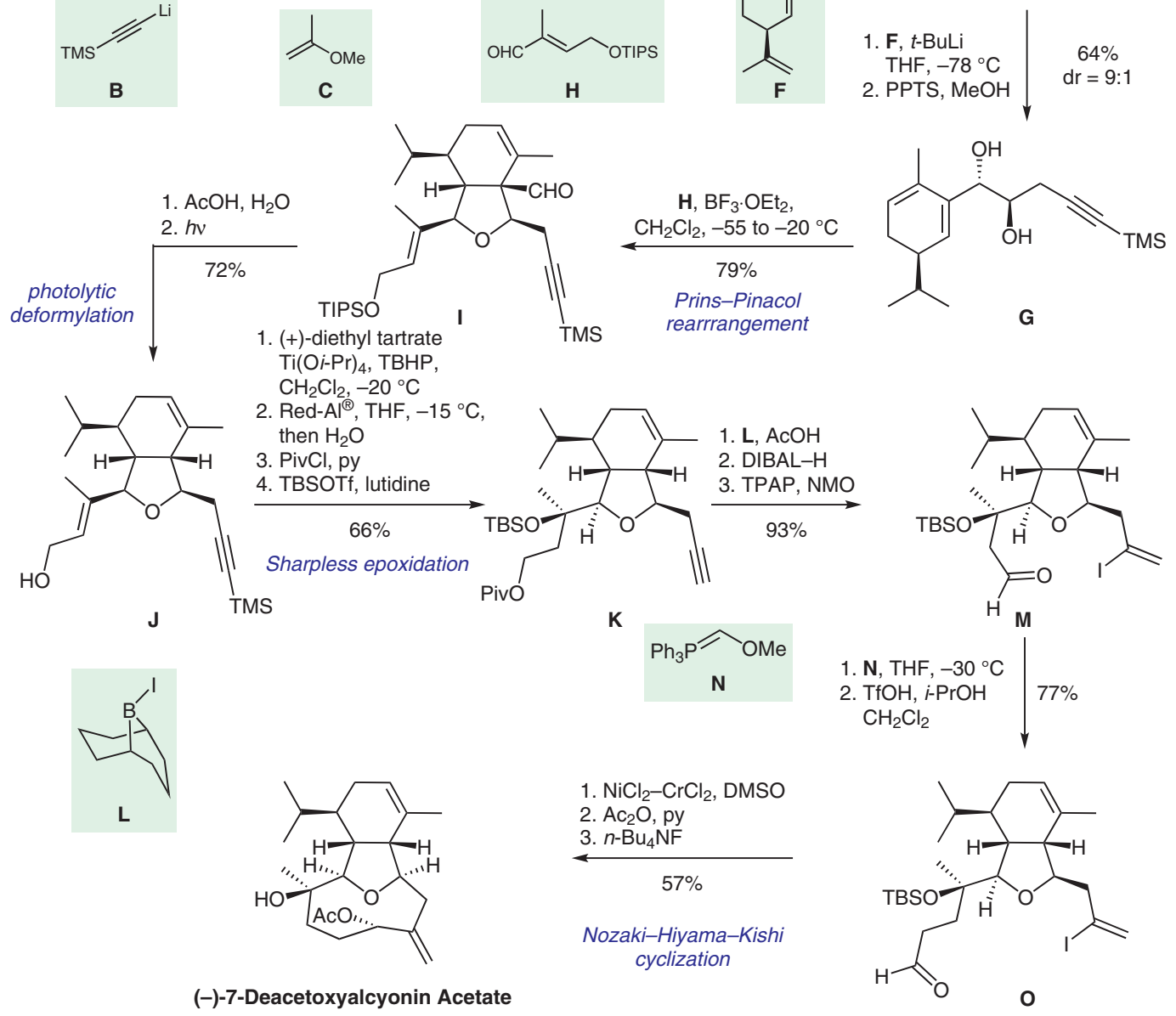

(-)-7-Deacetoxyalcyonin Acetate
1. $\mathrm{NiCl}_{2}-\mathrm{CrCl}_{2}$, DMSO

2. $\mathrm{Ac}_{2} \mathrm{O}$, py

3. $n-\mathrm{Bu}_{4} \mathrm{NF}$

zaki-Hiyama-Kishi cyclization
Significance: The eunicellin diterpenes feature a synthetically challenging tricyclic ring system, including a hydroisobenzofuran and oxonane subunit. MacMillan and Overman reported in 1995 the first synthesis of a member of this natural product family in asymmetric fashion, confirming the relative and absolute configuration proposed by the isolation team. Highlights of this synthesis include use of a Prins-pinacol rearrangement to access the hydroisobenzofuran core as well as a photolytic deformylation of a $\beta, \gamma$-desaturated aldehyde.
Comment: The synthesis commences with regioselective opening of $\mathbf{A}$, which was converted into aldehyde $\mathbf{E}$ in three steps. Dienyl iodide $\mathbf{F}$ was accessed in three steps starting with (S)-carvone. Fusing the two fragments set the stage for Prinspinacol rearrangement, affording I as a single stereoisomer. Deprotection and photolytic deformylation afforded intermediate $\mathrm{J}$. The final oxonane ring was constructed using Nozaki-Hiyama-Kishi coupling, the natural product in two additional steps. 